\title{
Ke Ji*
}

\section{The linguistic features of ELF by Chinese users in China-ASEAN communication contexts}

\author{
中国-东盟交际语境下中国英语通用语使用者的语言特点
}

DOI 10.1515/jelf-2016-0020

\begin{abstract}
Based on the Chinese component of the Asian Corpus of English (ACE), this study focuses on the lexicogrammar features of ELF by Chinese speakers in China-ASEAN communication contexts. It is found that non-standard forms do exist systematically in high distance social talk by the Chinese ELF users of comparatively high English proficiency. Examples and analysis are provided to illustrate the common non-standard lexicogrammar features in terms of lexical innovation, non-standard use of prepositions, the omission of subjects, objects and copula, grammatical disagreement, subject pronoun copying and tag question. These non-standard forms appear to be adopted due to mother tongue transfer, facilitation of communication or exploitation of language resources. However, no misunderstandings occur due to the non-standard forms.
\end{abstract}

Keywords: lexicogrammar, Chinese ELF users, ACE, non-standard features 摘要: 基于亚洲英语语料库 (ACE) 中国部分的语料, 这个研究关注中国-东盟交 际语境下中国说话者使用英语作为通用语的词汇语法特征。研究发现非标准的 语言形式系统地存在于社交距离较远、英语水平较高的中国英语使用者之中。 文章通过例子和分析阐明常见的词汇语法特征包括词汇创新, 非标准的介词使 用, 主语、宾语和系动词的省略, 语法不一致, 主语代词重复和反意疑问句。 这些非标准形式的出现是母语迁移、促进交流或者利用语言资源的结果。然 而, 这些非标准形式并没有造成误解。

关键词: 词汇语法, 中国英语通用语使用者, 亚洲英语语料库, 非标准特征

*Corresponding author: Ke Ji, Griffith University, Brisbane, Australia, E-mail: Ke.ji2@griffithuni.edu.au 


\section{Introduction}

English is being widely used in Asia in commerce, trade and international relations. Bolton (2008) estimated that there are over 800 million English users in South Asia, Southeast Asia and East Asia. The growing importance of English in the education systems in most Asian countries stimulates its spread in this region. What's more, the fact that the Association of Southeast Asian Nations (ASEAN) has adopted English as the sole working language of the group in 2009 (Kirkpatrick 2008) gives English privileged status within the ASEAN community. The extended group ASEAN +3 includes the ten ASEAN members and three East Asian countries, namely, Indonesia, Malaysia, the Philippines, Singapore, Thailand, Brunei, Vietnam, Laos, Myanmar and Cambodia as well as China, Japan and Korea, with an approximate total of 448 million English speakers (based on the statistics provided by Bolton [2008: 6]). Schneider (2014: 249) recently argued that the growing importance of English in some Asian countries may "justify a reclassification of their categories." For example, English in the "Expanding Circle" countries of ASEAN has expanded beyond that circle and become more like "Outer Circle" states as English takes on an increasing number of roles. The three East Asian countries, China, Japan and South Korea, with their strong emphasis on English in their education systems, are moving to an "ESL-plus" status (Schneider 2014: 251-252).

As for the relations between China and ASEAN, the past ten years has witnessed increasing communication between both sides. The bilateral trade between China and ASEAN jumped to USD $\$ 480$ billion in 2014 from USD $\$ 60$ billion in 2003. ${ }^{1}$ The "Belt and Road" initiatives proposed by Chinese president in 2013 will further facilitate the exchange between China and ASEAN countries. A total of over 423,000 participants have attended the ASEAN-China Exposition and ASEAN-China Business and Investment Summit in the first ten years (20042013) and the number of participants is steadily growing with over 50,000 participants annually in the last three years. ${ }^{2}$ English serves as the main working language for participants in these conferences and seminars as well as on informal occasions such as shopping and going on tours. In China-ASEAN communication contexts, English is used as a lingua franca by multilinguals with native speakers seldom involved. This study focuses on the linguistic features of ELF by Chinese users in these specific communication contexts.

1 Retrieved January 2015 from http://finance.chinanews.com.

2 Retrieved October 2014 from http://www.caexpo.org. 


\section{The study of the linguistic features of ELF}

The study of ELF has been controversial since it became a subject for academic research from the mid-1990s. For ELF scholars, English is no longer viewed as being owned by native speakers, whose number accounts for only one-fourth of the total English users in the world. In contrast, it is argued that L2 users of English have the right to use the language creatively in their own ways to achieve communicative goals in real contexts. Seidlhofer (2011: 7) defines ELF as any use of English among speakers of different first languages for whom English is the communicative medium of choice. ELF scholars are attempting to summarize the nature and characteristics of ELF (Seidlhofer 2001, Seidlhofer 2004, Seidlhofer 2005, Seidlhofer 2009, Seidlhofer 2011; Kirkpatrick 2010a, Kirkpatrick 2010b, Kirkpatrick 2013; Jenkins et al. 2011; Cogo and Dewey 2006, Cogo and Dewey 2012) and are interested in identifying the lexical and grammatical forms in ELF interaction that differ from English as a native language features but do not appear to cause misunderstandings or communication breakdown in ELF contexts. In other words, ELF research aims to find out how speakers exploit the language in an innovative and diversified way to achieve successful communication.

The availability of large-sized corpora makes it possible to conduct systematic studies at the lexicogrammar level. The VOICE (Vienna-Oxford International Corpus of English), ACE (Asian Corpus of English) and ELFA (English as a Lingua Franca in Academic Settings) projects have begun to provide corpus data for this type of study. Seidlhofer's (2004) and other scholars' empirical research into ELF in a European context shows a number of shared lexicogrammatical characteristics, including the 3rd person zero, omitting articles, non-standard tag questions, and the overuse of certain common verbs. Seidlhofer (2009) claims that non-conformity to the standard code and native-speaker idiomatic usage can be seen as resulting from ELF users making effective strategic use of the language as a communicative resource. The formal features of ELF are motivated by the functions they are required to serve. Seidlhofer's findings have stimulated follow-up research in this area. Cogo and Dewey (2012: 112), through studying salient aspects of lexis and grammar in their data such as the 3rd person zero, prepositions, articles and collocations, aim to identify the interrelationship of pragmatics and lexicogrammar and the various motives and underlying causes that contribute to the emergence of new forms in ELF, which they conclude as illustrating redundancy, regularization, prominence, explicitness and semantics. For example, based on their analysis of corpus data, Cogo and Dewey (2012) claim that the use of the 3rd person zero is a stable in various settings and domains. They share the same view with Seidlhofer that the 3rd person zero is a way of exploiting redundancy. 
In Asian contexts, there have been comparatively few studies of ELF. An exception is Kirkpatrick (2010b) who provides a preliminary description of linguistic features of English as a lingua franca within ASEAN contexts, including phonological, lexical, grammatical features as well as the pragmatic norms and communicative strategies adopted by ASEAN speakers of ELF. At lexicogrammar level, the non-standard features of ASEAN ELF include the marking or nonmarking of plurals, frequent use of present simple verb form, preference for modal form would over will and the frequent use of preposition about. Kirkpatrick (2010b) claims that non-standard use in these contexts represents natural language development. Scholars, using the ACE corpus, have shown that the ELF of ASEAN speakers shares certain linguistic features (Kirkpatrick 2008; Deterding and Kirkpatrick 2006; Kirkpatrick and Subhan 2014). What's more, some of the features are shared by ELF users in Asian and European ELF contexts. For example, the non-marking of plurals or the plural marking of uncountable nouns, different use of prepositions, uniform question tags have been identified in ASEAN ELF context and European context (Kirkpatrick 2010b; Seidlhofer 2004). However, there is, to date, no detailed description of ELF used by Chinese speakers. In this research, Chinese English (CE), especially spoken Chinese English is the focus. The characteristics of Chinese spoken English summarized by $\mathrm{Xu}$ (2010) will be used as a reference. On the basis of his spoken data, Xu (2010: 69) lists eight syntactic features of CE, including adjacent default tense, null subject or object, co-occurrence of connective pairs, subject pronoun copying, yes/no response, topic-comment, unmarked OSV and inversion in subordinate wh-clause.

\section{Methodology and data}

The Asian Corpus of English (ACE) comprises naturally occurring spoken English used as a lingua franca between Asian multilinguals. ACE comprises some one million words (equivalent to about 110 hours of recorded data) and became freely available online to researchers in September 2014 (http://corpus.ied.edu. hk/ace/). Nine teams in East Asia and Southeast Asia were involved in collecting data for ACE.

The author is a member of the ASEAN-China data collection team, and these data will form the primary data to be used in this research (Table 1).

The Chinese component of ACE was collected and transcribed at Guangxi University. There are a total of 45 speakers, with 22 Chinese L1 and 18 from ASEAN plus Japan and Korea. Only five out of the 45 speakers in the data are 
Table 1: The Chinese subset of ACE.

\begin{tabular}{|c|c|c|c|c|c|c|c|c|}
\hline \multirow[b]{2}{*}{ Origin } & \multirow[b]{2}{*}{ Chinese } & \multicolumn{2}{|r|}{ Speaker } & \multirow[t]{2}{*}{ Length } & \multirow[b]{2}{*}{ Politics } & \multirow[b]{2}{*}{ Economics } & \multirow[b]{2}{*}{ Entertainment } & \multirow{2}{*}{$\begin{array}{l}\text { Topics } \\
\text { Others }\end{array}$} \\
\hline & & $\begin{array}{l}\text { Other } \\
\text { Asian }\end{array}$ & $\begin{array}{l}\text { Non- } \\
\text { Asian }\end{array}$ & & & & & \\
\hline No. & 22 & 18 & 5 & & 8 & 3 & 3 & 4 \\
\hline Total & & & 45 & $7 \mathrm{H} 27 \mathrm{M}$ & & & & 18 \\
\hline
\end{tabular}

from non-ASEAN +3 countries. The first languages of speakers include Mandarin, Japanese, Thai, Filipino, Korean, Malay, Maldivian, Vietnamese, Indian, German and English. All but two of the Chinese speakers, who are unidentified, have university degrees and above. They are able to use English at their work and many of them have experience of study or work overseas.

The subset used in this research consists of 18 recordings, each lasting between 20 minutes to 40 minutes, with a total length of seven hours and 27 minutes. The recordings are from live talk shows broadcast on China Central Television Station's (CCTV) news channel, government websites and broadcast seminars, and all involve interactions between Chinese and other Asians discussing, in English, current issues. The recordings mainly come from the formal talk shows Dialogue and China Talk and the informal talk show Crossover. These focus on political and economic issues. One of the recordings is a Q\&A session of a China-ASEAN official seminar discussing China-ASEAN border customs. The topics cover a wide range of subjects including politics, economics, diplomacy, technology, energy, tourism, sports, women's issues, fashion and the lives of pop stars. The detailed information of the speakers and the context of communication enable the researcher to identify the specific features of the communication, including the mode of communication, the type of discourse and the proficiency level of the speakers (cf. Table 2). All these contribute to a more targeted study.

The original recordings were downloaded directly from Chinese official websites or broadcast resources and converted into WAV format audio files. Once the data had been collected and converted, they were transcribed using

Table 2: Features of the conversations.

Mode

Uses

Users
Naturally occurring, semi-structured

Specialised or technical discourse

High social distance, well-educated, use English at work 
VoiceScribe. The concordance software on ACE website and a free concordance software Antconc 3.2.1w were used to find out the common non-standard features of ELF in the data. As this research is aimed at the non-standard linguistic features of Chinese ELF users, only the data of the Chinese speakers are used here.

\section{Results}

After examining all the non-standard forms used by Chinese ELF speakers in the data, some salient lexicogrammar features can be identified. The analysis of the data will focus on lexical or phrasal innovation, the use of prepositions, omission of subject, object and copula, grammatical disagreement, subject pronoun copying (SPC) and tag questions.

\subsection{Lexical or phrasal innovation}

Seidlhofer (2011: 111) illustrates how ELF users exploit linguistic resources by using newly coined words and refers to the underlying encoding possibilities as virtual language. Similar examples are also found in the data by Chinese speakers.

Examples:

(1) ...hh we are talking about the MODEL of singapore and the $\langle$ pvc $>$ incertainties $</$ pvc $>$ that asia is facing

(2) many countries you mentioned have a very high expectation on china this is high time for china <fast> to do something significantly </fast $>$ ok so what kind of thing china can do significantly i think two categories category one just like $\langle$ spel $\rangle \mathrm{u} \mathrm{s}</$ spel $\rangle$ japan or south korea $\langle$ pvc $\rangle$ expectors $</$ pvc $>$ say you chinese (in your hand) a lot of cards (.)

(3) i think that is $\langle\mathrm{pvc}\rangle$ the must $\langle/ \mathrm{pvc}\rangle$ we need to discuss on common visions...

(4) well i mean you you play you used to play table tennis (.) $<$ pvc $>$ oftenly $\langle/ \mathrm{pvc}\rangle$

(5) $<$ pvc $>$ givently $</$ pvc $>$ political instability and ability as well

(6) in general to say and north korea is very smARtly make use of the differences 
The coined words or expressions in bold letters listed above can be classified as wrong, as they cannot be found in a standard English dictionary. But they do occur in these conversations, and without causing any misunderstandings. In example (1), the speaker used the self-invented word incertainties rather than uncertainties. In fact, the same speaker has been found using the correct form uncertainties at other times. It can be inferred that when a speaker is not sure which one is the correct form or cannot think of the correct one during the conversation, he/she would make up a new word on the spur of the moment according to the rules of English word formation in order to keep communication going. This kind of exploitation of language resources is also seen in example (2). The coined word expectors rather than anticipates is used referring to someone who can predict what might happen. Other examples with suffix "er" added, referring as a person, are found in the subset of ACE, such as gobetweener and red-shirter. In example (3), the modal word must is used as a noun in order to stress the speaker's point of view. Examples (4) and (5) can possibly be explained by the speakers' emphasis on the function of the word as an adverbial and so the adverbial marker ly is added. Example (6) is the speaker's attempt at generally speaking or in general. In general to say, however, can be easily understood as equivalent to generally speaking. These invented words or phrases are created by the speakers at the spur of the moment. They tend to conform to English word formation processes. Without interrupting the flow of communication, Chinese ELF users are able to create new words or phrases to facilitate communication.

\subsection{Prepositions}

Cogo and Dewey (2012) claim that the use of prepositions demonstrates a strong regularity of semantic value in ELF settings. The preposition about has been identified as an over-used all-purpose preposition (Kirkpatrick 2010b; Cogo and Dewey 2012).

In the Chinese component of the data, the non-standard use of prepositions is common, with a total of 71 examples found; these have been classified into three categories (cf. Table 3). A variety of prepositions are used in non-standard ways, accounting for $44 \%$ of all non-standard uses. Twenty-four per cent of the examples are with an additional use of prepositions, where they would not be used in standard English. In contrast, 32\% represent omissions of prepositions in cases where they would be included in most standard forms. 
Table 3: The non-standard use of prepositions (71 examples).

\begin{tabular}{lccc}
\hline Extra & Variation & Omission & Total \\
\hline 17 & 31 & 23 & 71 \\
$24 \%$ & $44 \%$ & $32 \%$ & $100 \%$ \\
\hline
\end{tabular}

Below are some examples.

\subsubsection{Extra use of prepositions}

(7) so in currently we are discussing the er new resolution

(8) china is in rising and south south korea is in rising

(9) try: to explain (1) to my japanese friends about (.) what was going on in china

(10) mister obama doesn't even call to kim jong-un

(11) you mentioned about the governance reform in the world bank

(12) <spel $>$ i m f </spel $>$ is er (.) ad- advocating for full convertibility

(13) whenever $<$ spel $>$ u s $</$ spel $>$ and china (.) reduce on (no) inten-intervention on the interkorean

(14) we are going to discuss more about HIS music dream

(15) i mean contact with them

The preposition about can be identified as the most common extra preposition used as in discuss about, mention about, explain about, know about (see examples [9], [11], [14]) and is used to replace other prepositions (see examples [20] to [22] below) Similar examples have been found by other scholars in different contexts (Cogo and Dewey 2012; Kirkpatrick 2010b).

The extra use of certain prepositions sometimes carries semantic value, as shown in examples (7) and (8). The extra use of in (in currently, in rising) may emphasize the continuation of the process. Some extra use can be seen as the influence of the mother tongue, like call to, and contact with. In Chinese, people would say 打电话给... 'call to NP', 和...联系 'with NP contact'.

\subsubsection{Different use of prepositions}

The standard forms are suggested at the end of each example in brackets.

(16) however we also see very proactive role by the thai military (of) 
(17) the pen grip players have any advantages (.) to the (.) tennis grip (.) players (over)

(18) by the same time leave space for possibilities (at)

(19) for a large degree singapore and china (to)

(20) there is a burgeoning public awareness about the importance of maritime stakes (of)

(21) they are holding the breath about hh uncertainty and unpredictability (for)

(22) are you surprised about the rise of asia (at)

(23) there is still speculation and suspicion around china's motives (of)

A variety of prepositions are used in non-standard forms, but are understandable substitutes. In examples (16) to (19), for example, have any advantages to rather than the standard form of have any advantages over and for a large degree rather than to a large degree do not cause misunderstandings. It is interesting to note that some speakers may use the standard and the non-standard preposition in different places. For example, the person who says for a large degree in (19) also used to a large degree in the same dialogue.

\subsubsection{Omission of prepositions}

The suggested prepositions are listed at the end of each example and the places where prepositions are supposed to be are marked with <om>.

(24) the hu:ge challenges: (.) be lying <om> the tips of the huge iceberg (on)

(25) northeast asia pointed $<$ om $>$ each other as well (at)

(26) because my ambition is was <om> become a doctor or pharmacist or chemist yeah (to)

(27) so her idea is <om> give you some pieces (to)

(28) other european er er (.) powers have agreed to join $<$ om $\rangle\langle$ spel $>$ a i i b $<$ spel $>$ (in)

(29) the exclusive nationalism hh that prevailed (.) <om $>$ both countries (in)

Omission of prepositions is found mainly in three contexts. First, to is found omitted in the infinite to do as a predictive, such as in examples (26) and (27), which may be a result of mother tongue influence. In Chinese, a predictive can be directly followed by a verb. Second, prepositions are omitted in the cases of showing position or direction, such as in examples (24) and (25). Third, prepositions which follow an intransitive verb are omitted, such as in examples (28) and (29). 


\subsection{Grammatical disagreement}

There are four grammatical disagreement categories discussed here, namely, singular/plural disagreement, subject/verb disagreement, disagreement in the there be structure and others (cf. Table 4).

Table 4: Grammatical disagreement (81 examples).

\begin{tabular}{lcccc}
\hline Singular/plural & Subject/verb & there be structure & Others & Total \\
\hline 47 & 21 & 5 & 8 & 81 \\
$58 \%$ & $26 \%$ & $6 \%$ & $10 \%$ & $100 \%$ \\
\hline
\end{tabular}

Below are some examples of disagreement.

\subsubsection{Singular-plural disagreement}

(30) all the international organization always say competition is

(31) display (.) a different perspectives from asia

(32) social progress means for the populations

\subsubsection{Subject/verb disagreement}

(33) well china firmly believe the current complex er issue of nuclear

(34) bilateral investment always carry this kind of say geo political dif- challenge

(35) so $\mathrm{i}$ think (.) the key words is the dialogues not confrontation

(36) the rent are super high

\subsubsection{There be structure}

(37) there is so much things

(38) is there any other sports items you are interested

\subsubsection{Others}

(39) other players also want to come into region play its role

(40) to join in our programme to talking about their experience 
Out of a total of 81 examples of disagreement, more than half (58\%) are related to singular-plural disagreement (see examples [30] to [32]). There are many other examples such as all the country, two city, one of our target, another issues, a big chances, a lot of international industry. Most (34 out of 47) examples of singular-plural disagreement show the non-marking of plural nouns, as in (30). Ten out of 47 examples show the unnecessary marking of plurals, as in (31). Only three examples show the plural marking of uncountable nouns, as in (32).

The second category, subject-verb disagreement, is most common (16 out of 21) with the 3rd person zero, such as in examples (33) and (34). For the rest, a plural subject is followed by a singular linking verb or vice versa, as shown in examples (35) and (36). The disagreement of linking verbs with their subjects can also be found in there be structure sentences, as in examples (37) and (38). However, only singular linking verbs are found in all these examples of disagreement in the there be structures. It can be inferred that in oral communication, the singular form there is is more likely to be used, almost as a routine formula. In fact, the use of there is plus plural nouns is very common in all varieties including standard varieties. Five out of the eight "other" examples involve the use of to followed by the present or past participle rather than the infinitive, as shown in (40).

\subsection{Non-standard omission}

Cogo and Dewey (2012) believe that the omission of the object, pronouns and copula be, as the features of ELF lexicogrammar, is the result of speakers actively exploiting redundancy for the purpose of efficiency of communication. Similar features are also found here in terms of subject omission (20\%), object omission (22\%), copula omission (15\%), preposition omission (35\%) and “others" ( $8 \%$ ) (cf. Table 5). The omission of prepositions accounts for the largest part of all the omission categories, as discussed above.

What follows are some examples (the omission places are marked by <om>).

Table 5: Non-standard omissions (61 examples).

\begin{tabular}{lccccc}
\hline Subject & Object & Copula & Preposition & Others & Total \\
\hline 13 & 14 & 10 & 23 & 5 & 65 \\
$20 \%$ & $22 \%$ & $15 \%$ & $35 \%$ & $8 \%$ & $100 \%$ \\
\hline
\end{tabular}




\subsubsection{Subject}

(41) well (.) <om> must be a very interesting topic @@@

(42) but <om > could not compete with us

(43) if <om $>$ still can not solve this problem

\subsubsection{Object}

(44) we have to double our efforts to reconcile <om>

(45) S2: so did you buy anything today

S6: i'm going to buy <om>

(46) er quite similar with <om> doctor lee mentioned

\subsubsection{Copula}

(47) but when $\mathrm{i}<\mathrm{om}>$ holding the mike

(48) you know china and <spel $>$ u s </spel $>$ differences <om > deepening

(49) how <om> you think about this game?

In the data, all the subjects omitted are anaphoric pronouns, which refer to something mentioned earlier. Speakers would therefore be unlikely to misunderstand the omissions, as they all clearly know what is being talked about, as illustrated in examples (41) to (43).

The objects omitted include various content words and pronouns which can be inferred by the speakers. The omissions occur mainly due to transgressing transitivity as shown in example (44). The transitive verb reconcile occurs without an accompanying object (but which has been explicitly stated previously). This is an example of what Cogo and Dewey (2012: 88) refer to as "avoid redundancy and enhance the communicative efficiency." In addition, the word reconcile in Chinese 和解 can be used in this context without an object. The influence of Chinese language is a possible reason for omission, as seems to be the case in example (45). When S2 asked did you buy anything today? S6 answered with I'm going to buy rather than Yes, which is a very typical Chinese response. In Chinese, the answer normally needs to repeat the verb in the question rather than just saying yes or no. Another example of object omission is found in the noun clause beginning with what. In example (46), what is omitted in the noun clause but the sentence is still easily understood. 
The omission of copulas accounts for only a small part (15\%). As copulas do not convey much semantic value, their omission in these contexts is unlikely to cause any misunderstanding.

\subsection{Subject pronoun copying (SPC)}

In the following examples of subject pronoun copying, each subject is "copied" into a pronoun. For example, in example (50), the pronoun this refers to asean plus three. $\mathrm{Xu}$ (2010: 77) claims that "the topic prominent nature of Chinese make SPC a feature of spoken CE (Chinese English)" and the use of SPC in his spoken data seems unmarked. SPC is also identified as one of the features of the speech of these Chinese ELF users.

Some examples of SPC:

(50) there was already asean plus three (.) this trade mechanism

(51) given the fact that <spel $>\mathrm{d}$ p r k </spel $>$ it is a sovereign country

(52) even those residents er: who live near the bird's nest they can not find the main torch (.) where is the...

(53) different local customs sometimes they have different (.) understanding or explanation

(54) shanghai ports and dalian ports (1) they have different situations sometimes so it's...

\subsection{Tag question}

Some scholars have found out that ELF users tend to use tag questions less frequently in their interactions and the forms are simpler and invariant in many different varieties, for example isn't it? in African English (Schmied 1991, cited from Kirkpatrick 2010b) and Singaporean English. In the European ELF context, Seidlhofer (2004) also identifies the non-standard tag questions like or no? instead of shouldn't they?. As for Chinese English, Xu (2010) summarizes three tag variation strategies found in his data. For example, A-not-A question is a result of transfer from Chinese language and a variety of invariant tag questions, such as got it?, understood? found in the communication settings in short stories. And the third variation lies in the response to tag questions. In his short story data, Xu (2010: 105) found that the second speaker simply elaborated on their own responses rather than providing direct yes or no answers. 
In this study, only 12 examples of tag questions used by Chinese ELF speakers occur in the data. However, they are highly uniform in the use of right as a question tag in 9 out of the 12 examples (examples [55] to [58]). The other three examples (examples [59] to [61]) are also invariant tags: yeah?, huh? and is it?. The consistent use of right and other simple tags in tag questions by Chinese ELF users may be the result of L1 transfer, as Chinese use the invariant tag 是吗/对吗? 'is it right?' as a tag question. It is also possible that the simple and consistent tag right makes communication easier and clearer, and this is one reason why it is used in ELF interaction.

(55) make a living by singing (.) right?

(56) you you guys er met each other before right?

(57) something like to be seen right?

(58) i'm sure you will agree with me right?

(59) well i mean you you play you used to play table tennis oftenly yeah?

(60) so music isn't easy huh?

(61) he is part of the power struggle is it?

In terms of response to tag questions, ten examples by Chinese ELF users are found in these data. However, unlike the results found in Xu's data, nearly all the tag questions are given a definite response except one (example [70]) where other speakers responded by laughing together as they all agree with what had been said. Examples (62) to (66) are responded directly by yes/yeah/ okay or no and examples (67) to (69) are given a definite statement by the second speaker.

(62) S1: so music isn't easy huh?

S5: no (.) I do not know it is very hard

(63) S1: you you guys er met each other before right?

S4: actually er we knew each other back in er the united states

S5: yeah

(64) S1: the case with you guys is all different an- and you guys all you have is independence right?

S4: yes (.) because without a company (.) I think the good thing is that er we can control up timeline (.) and also $\langle 4\rangle \mathrm{my}\langle/ 4\rangle$

(65) S2: and have a lot fun with this right? $\langle 8\rangle$ at night $\langle/ 8\rangle$

S7: $\langle 8\rangle$ yes $\langle/ 8\rangle$ to group it to $\langle 9\rangle$ buy it $\langle/ 9\rangle$ 
(66) S1: ... er we: we can get someone who speak in English so it's a much easier to the flow of communications $<3>$ right? $</ 3>$

S2: $\langle 2>$ okay $</ 2><3>\mathrm{mhm}</ 3>$ I'll try my best

(67) S2: so I think this could be advice for any inspiring $<7>$ musicians $</ 7>$ or vocalists out there right?

S1: $<7>$ that's right $</ 7>$

(68) S1: you have you have six people right?

S4: we have@@@@

(69) S2: <2> you have to be DOING </2> right?

S7: that is what I want

(70) S1: <1> something like to be $</ 1>$ seen right?

All:@@@

\section{Conclusion}

From the study of the Chinese subset of ACE, certain salient non-standard lexicogrammar features of ELF by Chinese users have been identified and include lexical innovation, the non-standard use of prepositions and omission, grammatical disagreement, SPC and tag questions. First, Chinese ELF users are able to invent new words or phrases, by following the English word formation principles, in order not to interrupt the flow of communication. These words are coined naturally in the context without causing any misunderstandings. Second, Chinese ELF speakers demonstrate a highly flexible use of prepositions. Prepositions with similar semantic meanings can be used interchangeably at the speaker's disposal. The omission and extra use of prepositions may be the result of mother tongue influence and the confusion between transitive and non-transitive verbs. Third, grammatical disagreements exist mostly in the non-marking and unnecessary marking of plurals. 3rd person zero is the most common occurrence of subject-verb disagreement used by these Chinese ELF speakers. Fourth, omissions of subjects and objects are found in about equal measure. All the omitted subjects are anaphoric pronouns which can be understood by the participants. The omission of objects occurs mostly when speakers transgress transitivity rules and/or are influenced by Chinese language patterns. Fifth, SPC, a common feature of spoken CE, can also be identified in these ELF contexts. What's more, tag 
questions are less frequently used by Chinese ELF users and most of the question tags are simple invariant tags like right or yeah.

These non-standard features are found in these formal and semi-formal ELF settings in the speech of Chinese ELF users with comparatively high English proficiency. They are adopted mostly due to mother tongue transfer, facilitation of communication or exploitation of language resources. It is noted that language change is seldom the result of a single cause but a highly complex process. The use of these non-standard forms do not necessarily cause misunderstanding in their ELF interactions. It is suggested that in this China-ASEAN ELF context, the non-standard forms of English can be accepted in a positive way rather than being treated as "errors."

Nonetheless, it is noted that these non-standard features are not exclusive to Chinese ELF users. Many of the features identified here are also found in other varieties of English and different ELF contexts. Therefore, we must be careful not to draw a definite and general conclusion about the linguistic features of a specific ELF user, such as these Chinese ELF users. The purpose of the research was to identify the non-standard features of the ELF used by Chinese speakers in a defined context. The findings indicate that certain non-standard features of ELF also occur in Chinese English. To what degree the features identified in this research are shared with those of Chinese English as a variety or ELF in other contexts needs further study. By focusing on Chinese ELF users, this research hopes to provide a preliminary study of ELF users in specific contexts, while, at the same time, contributing to the overall study of ELF use. It is also hoped that the findings may trigger a re-examination of the goal and approach of English teaching in local universities in China, especially those such as Guangxi University, which trains interpreters and translators to facilitate exchange between China and ASEAN. "Standard English" should not serve as the only goal for Chinese learners who will be communicating primarily with people from ASEAN countries.

\section{Appendix. Mark-up conventions}

Adapted from "The ACE manual: Date collection and transcription for the Asian Corpus of English” (version of 14 June 2011).

- Speaker IDs: Each speaker appears in sequence with the first being referred to as S1, the next S2 and so on.

- Intonation: When a rising tone is used, a question mark "?" is added immediately after the word. A full stop is used after a word with a falling tone: “.” 
- Emphasis: Capital letters are used to show emphasis.

- Pauses: A half second pause is marked as a full stop between two brackets “(.)” One second is expressed as "(1)", two seconds “(2)” and so on.

- Overlaps: Angled brackets are used to show more than one person speaking at the same time.

- Lengthening: Lengthened utterances are symbolized with a colon.

- Repetitions: All recorded repetition is represented in the corpus.

- Word fragments: A hyphen is used to symbolize the uncompleted part of a word.

- Laughter: It is represented by the “@” symbol. Each @ is the equivalent of one syllable of laughter.

- Uncertain transcription: Uncertain utterances are transcribed within brackets.

- Pronunciation variation and coinages: Words that cannot be found in the Oxford Advanced Learner's Dictionary fall into the pronunciation variations and coinages category, marked as PVC.

- Spelling out: If a word is spelt out or is pronounced using individual letters, then it is marked with "spel".

- Speaking modes: the pace, pitch, tone, style and method of speaking are marked, for example <fast $>$.

- Breath: Breathing is expressed as "hh".

\section{Corpus references}

ACE: http://corpus.ied.edu.hk/ace/

China-ASEAN Exposition: http://www.caexpo.org/statics/images/hg11th/ bigimg03.html

China news: http://finance.chinanews.com/cj/2015/01-30/7022026.shtml

VOICE: https://www.univie.ac.at/voice/

\section{References}

Bolton, Kingsley. 2008. English in Asia, Asian Englishes, and the issue of proficiency. English Today 24(2). 3-12.

Cogo, Alessia \& Martin Dewey. 2006. Efficiency in ELF communication: From pragmatic motives to lexicogrammatical innovation. Nordic Journal of English Studies 5(2). 59-94.

Cogo, Alessia \& Martin Dewey. 2012. Analysing English as a lingua franca. A corpus-driven investigation. London, UK \& New York: Continuum International Publishing Group.

Deterding, David \& Andy Kirkpatrick. 2006. Emerging South-East Asian Englishes and intelligibility. World Englishes 25(3/4). 391-409. 
Jenkins, Jennifer, Alessia Cogo \& Martin Dewey. 2011. Review of development in research into English as a lingua franca. Language Teaching 44(3). 281-315.

Kirkpatrick, Andy. 2008. English as the official working language of the Association of

Southeast Asian Nations (ASEAN): Features and strategies. English Today 24(2). 27-34.

Kirkpatrick, Andy. 2010a. Researching English as a lingua franca in Asia: The Asian Corpus of English (ACE) project. Asian Englishes 13(1). 4-18.

Kirkpatrick, Andy. 2010b. English as a lingua franca in ASEAN. A multilingual model. Hong Kong: Hong Kong University Press.

Kirkpatrick, Andy. 2013. The Asian Corpus of English: Motivation and aims. In ShinÕichiro Ishikawa (ed.), Learner corpus studies in Asia and the world, 17-30. Kobe: Kobe University Press.

Kirkpatrick, Andy \& Sophiaan Subhan. 2014. Non-standard or new standards or errors? The use of inflectional marking for present and past tenses in English as an Asian lingua franca. In Sarah Buschfeld, Thomas Hoffmann, Magnus Huber \& Alexander Kautzsch (eds.), The evolution of Englishes. The dynamic model and beyond, 386-400. Amsterdam: John Benjamins Publishing Company.

Schneider, Edgar. W. 2014. Asian English-into the future: A bird's eye view. Asian Englishes 16(3). 249-256.

Seidlhofer, Barbara. 2001. Closing a conceptual gap: The case for a description of English as a lingua franca. International Journal of Applied Linguistics 11(2). 133-158.

Seidlhofer, Barbara. 2004. Research perspectives on teaching English as a lingua franca. Annual Review of Applied Linguistics 24. 209-239.

Seidlhofer, Barbara. 2005. English as a lingua franca. ELT Journal 59(4). 339-341.

Seidlhofer, Barbara. 2009. Common ground and different realities: World Englishes and English as a lingua franca. World Englishes 28(2). 236-245.

Seidlhofer, Barbara. 2011. Understanding English as a Lingua Franca. Oxford, UK: Oxford University Press.

Xu, Zhichang. 2010. Chinese English: Features and implications. Hong Kong: Open University Press.

\section{Bionote}

\section{Ke Ji}

$\mathrm{Ke} \mathrm{Ji}$ is a PhD candidate of Griffith University in Australia, with 18 years' teaching experience of English majors at Guangxi University in China. She received her MA in Foreign Applied Linguistics from Guangxi University. Her current research interests include the study of English as a lingua franca in the context of China-ASEAN communication and its implications for English teaching in China. She is the head of the ACE China team. 